\title{
Possible Deviations in the Determination of Bulk Solid Characteristics, Caused by the Loading Mechanism of the Jenike Shear Cell
}

\author{
F. J. C. RADEMACHER and G. HAAKER \\ Department of Mechanical Engineering, Twente University of Technology, P. O. Box 217, 7500 AE Enschede \\ (The Netherlands)
}

(Received April 29, 1984; in revised form October 20, 1985)

\section{SUMMARY}

In the literature ample attention is given to the assumptions on which the interpretation of shear-test results from a Jenike shear tester are based. Very little is said, however, about the influence on the test data of the construction of the apparatus itself. In the work described here, the authors have investigated the influence of the loading mechanism on the results. The original Jenike-type tester and a slightly modified one are considered.

From the equilibrium conditions, the real normal and shear stresses on the assumed shear plane were derived, which were found to deviate from the external applied stresses. The deviations in the primary results and derived data were quantified by introducing correction factors, the boundary values of which could be calculated.

Experiments with three different bulk materials were performed to measure the relevant quantities and to verify the assumptions used in theoretical analysis. Furthermore, the real normal stress on the shear plane was measured directly. From these measurements the experimental correction factors could be derived, which appeared to lie within the boundaries as theoretically predicted.

In general it may be concluded that the yield loci and their derived quantities as determined by a properly used Jenike shear tester are, as a rule, suitable for design purposes of e.g. silos. For comparison of results from different testing techniques, however, the deviations introduced by the loading mechanism cannot be neglected.

\section{INTRODUCTION}

The Jenike shear tester $[1,2]$ offers a quick and reproducible method for the determination of the flow properties of bulk solids.

The interpretation of the results is based on assumptions which have been widely discussed in the literature [3]. However, the external loading mechanism of the shear cell itself will directly influence the results and requires some consideration. By both analysis and experiment, the parameters dominating this influence are investigated and possible deviations in the results are quantified.

\section{ANALYSIS}

\section{Introduction}

In this section, two different methods will be distinguished, one in which the weight of the ring and its content are added to the applied load in determining the normal force on the failure plane and another in which they are not included.

Referring to Fig. 2, the measured yield loci are indicated by (1) and (2) respectively. With the aid of two sets of correction factors to be introduced, the 'real' yield locus indicated by (3) can be obtained for both cases. Once this is done, the correction factors for the unconfined yield pressures, the flow functions and the effective coefficients of friction follow readily. It is assumed that locus (1) obeys the Warren-Spring equation [4] .

In the analysis, only the cases where the ring stays in contact with the base are considered, since the situation after spontaneous lifting of the ring is too complicated for a 


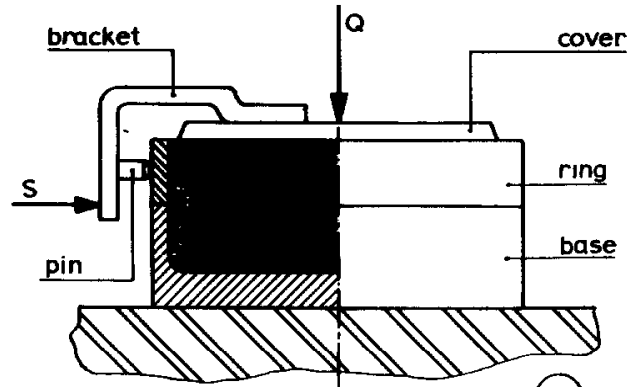

(a)

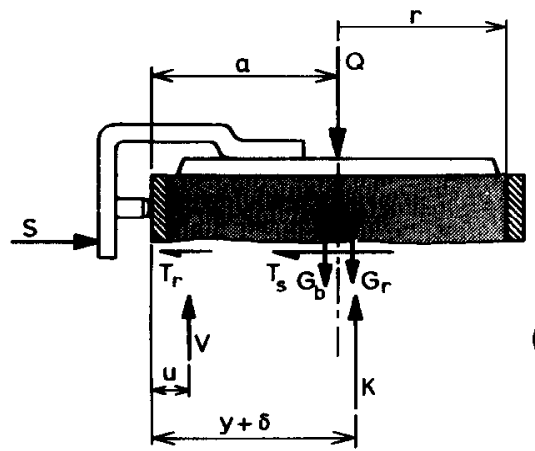

(b)

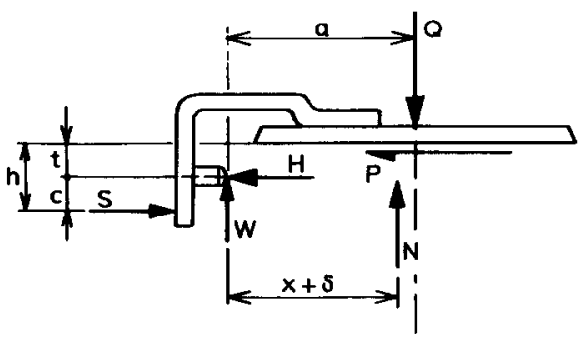

(c)

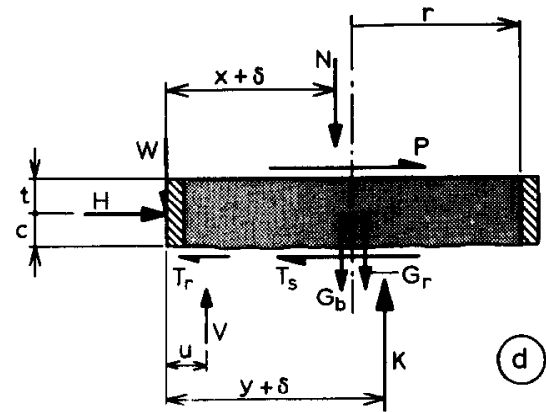

(d)

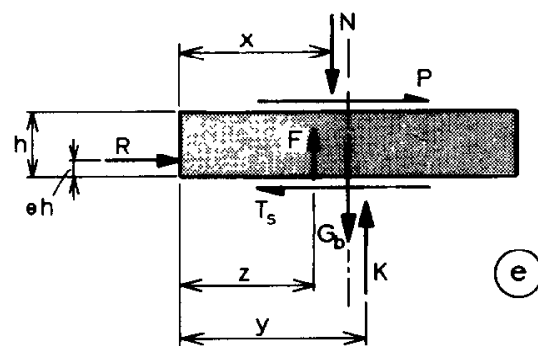

(e)

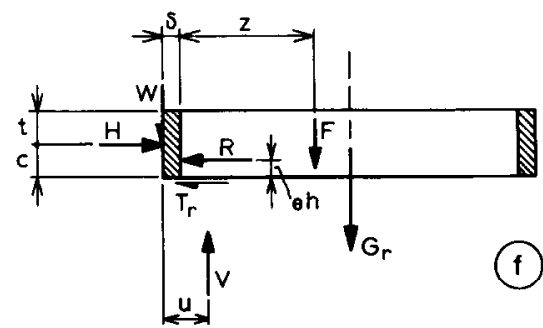

Fig. 1. Illustration of the real normal force $K$ and shear force $T_{\mathrm{s}}$ exerted on the plane of shear of the bulk solid in case of the original Jenike shear cell. The weight vectors of bulk $G_{\mathrm{b}}$ and ring $G_{\mathrm{r}}$ coincide with the centre line.

satisfactory theoretical treatment. However, the authors believe that the limited analysis and the experiments will together provide some insight into the boundaries within which the yield loci might be influenced by the parameters of the shear cell.

The authors have observed over the years, for a relatively large number of cohesive materials, that the ring remains in contact with the base throughout the complete measuring cycle and that the pin in a number of cases slides over the ring surface, the motion resulting from both translation and rotation of the cover. This is further discussed in the section on Experiments.

Moreover, for the purpose of the analysis, the following assumptions are made:

(i) the parts of the equipment do not deform; (ii) the shear zone is a horizontal plane;

(iii) coefficients of friction between pin and ring $\left(\mu_{\mathrm{p}}\right)$ and between ring and base $\left(\mu_{\mathrm{r}}\right)$ are constant;

(iv) the shear force $S$ acts horizontally;

(v) the load $Q$ acts vertically.

In this paper, the Jenike device will be analysed first and then a modified version.

\section{Correction factors for the Jenike tester}

From the equilibrium conditions, Fig. 1, it follows that

$\sigma_{\mathrm{c}}=\frac{K}{A}=(1-\Omega)\left[1-\mu_{\mathrm{p}}(1-\epsilon) \frac{\tau}{\sigma}\right] \sigma+\sigma_{\mathrm{b}}$

and

$\tau_{\mathrm{c}}=\frac{T_{\mathrm{s}}}{A}=\left\{\left[1-\mu_{\mathrm{p}} \mu_{\mathrm{r}}(1-\Omega)(1-\epsilon)\right]\right.$ 


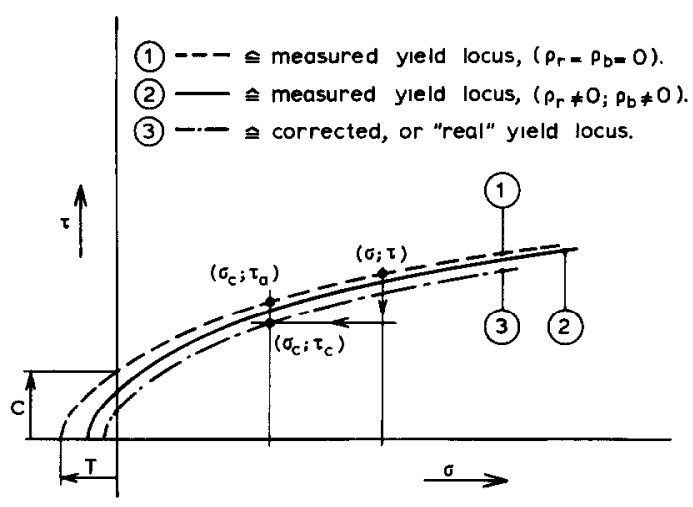

Fig. 2. Yield loci. Due to the smaller values of the corrected stresses, the point $(\sigma ; \tau)$ does not belong to the yield locus (1) but to yield locus (3) instead. In plotting yield locus (1), the body force of the ring and its content was neglected; for yield locus (2) it was taken into account.

$$
\left.-\mu_{\mathbf{r}}\left(\Omega+\frac{\sigma_{r}}{\sigma}\right) \frac{\sigma}{\tau}\right\} \tau
$$

where

$$
\left.\begin{array}{l}
\sigma=\frac{Q}{A} \\
\tau=\frac{S}{A}
\end{array}\right\}
$$

$\left.\begin{array}{c}\sigma_{\mathrm{b}}=\frac{G_{\mathrm{b}}}{A} \\ \sigma_{\mathrm{r}}=\frac{G_{\mathrm{r}}}{A}\end{array}\right\}$

$\sigma_{\mathrm{b}}$ and $\sigma_{\mathrm{r}}$ represent the influence of the weight of the entrapped bulk above the shear plane and that of the ring respectively.

As described in the section on Experiments, in a number of cases the pin did not slide over the ring. The direction $\phi$ of the force vector of the pin is then unknown. This means that situations in which the pin is tending to move upward, without really doing so, cannot be excluded. The case of an upward frictional force exerted on the ring can easily be allowed for by changing the sign in front of $\mu_{\mathrm{p}}$ in eqns. (1) and (2). It also allows for the determination of those $\phi$-values for which the ring is (just) not lifted.

Equations (1) and (2) show that the actual stress situation $\left(\sigma_{\mathrm{c}}, \tau_{\mathrm{c}}\right)$ in most cases is lower than the external applied stresses $(\sigma, \tau)$, leading to different yield loci, as represented in Fig. 2.

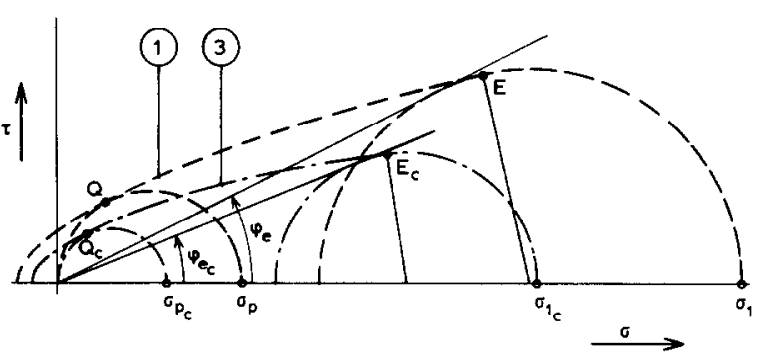

Fig. 3. Consequences of a corrected yield locus. Among others there is a change in the unconfined yield pressure $\left(\sigma_{\mathrm{p}_{\mathrm{c}}}\right.$ instead of $\left.\sigma_{\mathrm{p}}\right)$; in the location of the terminal point $\left(E_{c}\right.$ instead of $\left.E\right)$ and therefore in the major consolidation stress $\left(\sigma_{1}\right.$ instead of $\left.\sigma_{1}\right)$, and also in the effective angle of friction $\left(\phi_{\mathrm{e}_{c}}\right.$ instead of $\phi_{\mathrm{e}}$ ).

The consequences of a corrected yield locus are illustrated in Fig. 3 where the uncorrected yield locus $₫$ and the corrected yield locus (3) are shown. Three important physical quantities, the unconfined yield pressure $\sigma_{\mathrm{p}}$, the flow function (ff $=\sigma_{1} / \sigma_{\mathrm{p}}$ ) and the effective angle of friction $\phi_{\mathrm{e}}$ will change. The quantification of these changes must preferably be obtained from both the experiments and the analysis. The Warren-Spring equation [4] has been used to describe uncorrected yield locus (1) in the analysis. It has been used in the form

$\tau=C\left(\frac{\sigma}{T}+1\right)^{1 / n} \approx \psi T\left(\frac{\sigma}{T}+1\right)^{1 / n}$

Although this equation has some deficiencies, it represents a sufficiently good approximation for the determination of the possible deviations or 'correction factors' of the relevant physical properties of bulk materials. These are defined as

$\mathrm{CF}_{\sigma_{\mathrm{p}}}=\sigma_{\mathrm{p}_{\mathrm{e}}} / \sigma_{\mathrm{p}}, \mathrm{CF}_{\mathrm{ff}}=\mathrm{ff} \mathrm{c}_{\mathrm{c}} / \mathrm{ff}, \mathrm{CF}_{\mu_{\mathrm{e}}}=\mu_{\mathrm{e}_{\mathrm{e}}} / \mu_{\mathrm{e}}$

and

$C F_{\mathrm{yl}}=\left(\tau_{\mathrm{c}} / \tau_{\mathrm{a}}\right)_{\sigma_{\mathrm{c}}}$

for the unconfined yield pressure, the flow function, the effective coefficient of friction and the yield locus itself, respectively. These correction factors have been quantified, using a computer. Some of the results are presented in Tables 1 and 2.

\section{Correction factors for the modified Jenike tester}

The modifications of the Jenike tester and the effect on the forces are illustrated in 


\section{TABLE 1}

Possible correction factors for both the original Jenike shear cell and the modified one. Body forces of the ring and its content neglected $\left(\rho_{\mathrm{r}}=\rho_{\mathrm{b}}=0\right)$.

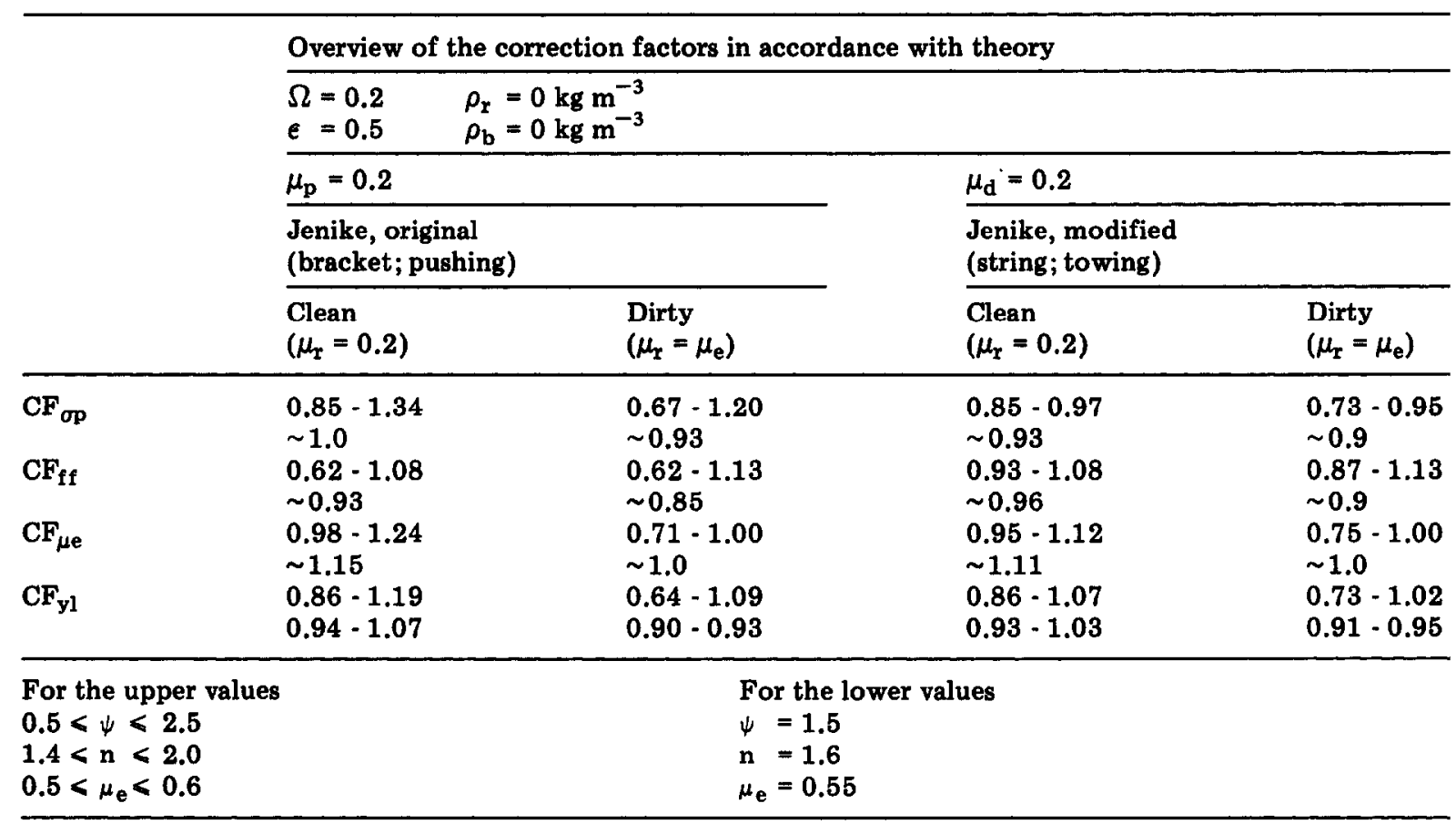

\section{TABLE 2}

Possible correction factors for both the original Jenike shear cell and the modified one. Body forces of the ring and its content are taken into account $\left(\rho_{\mathrm{r}} \neq 0\right.$ and $\left.\rho_{\mathrm{b}} \neq 0\right)$.

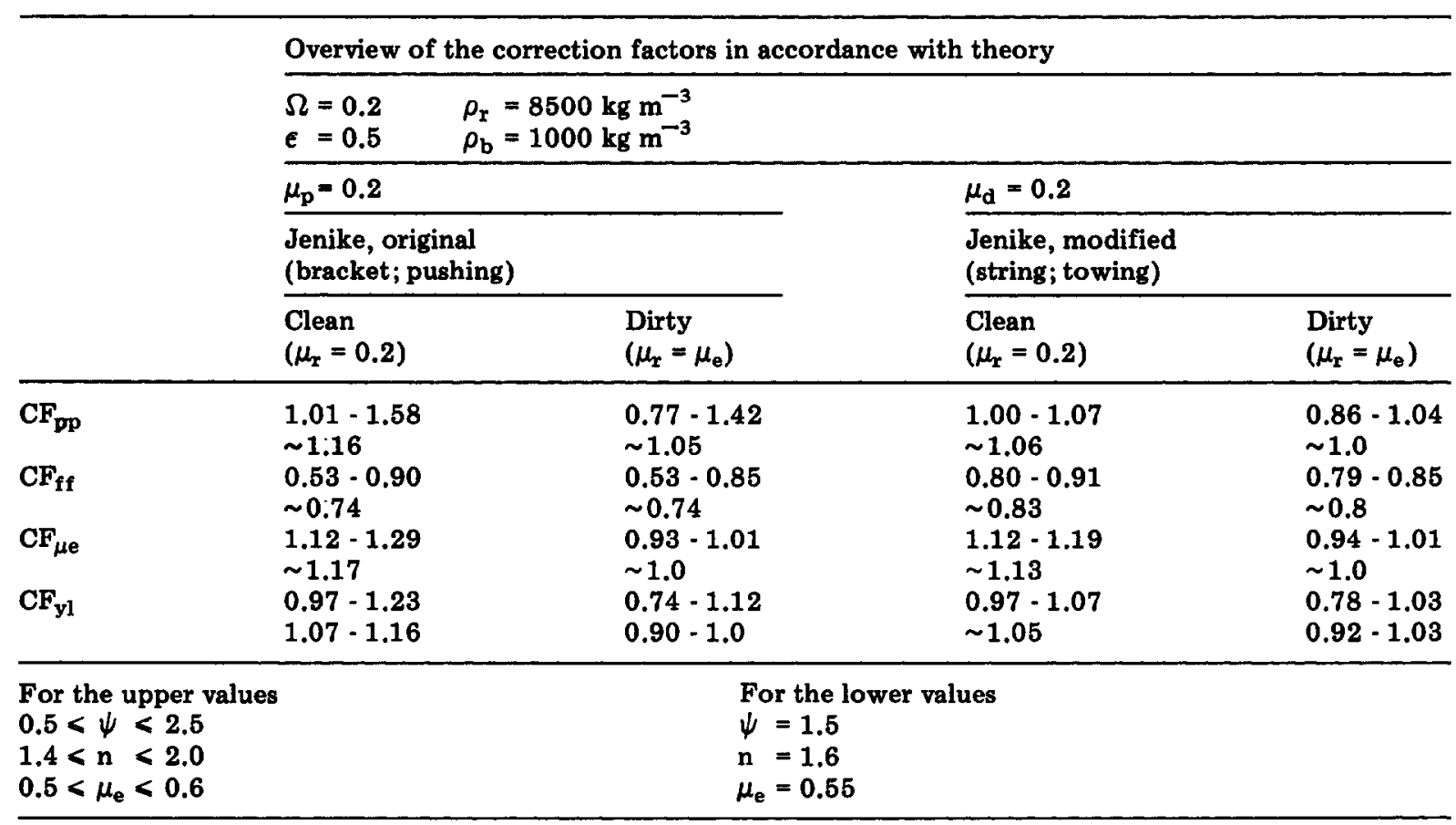


Figs. 4(a) and 4(b), respectively. The ring is equipped with a simple brace and piano-wire, which can be pulled, so that the horizontal shear force vector passes through the idealised plane of shear.

From experimental observation, it appeared that during shear the ring remains in contact with the base at location (1), Fig. 4(a), but separates a few tenths of a millimetre in the majority of cases at location (2). It has therefore been assumed that the force between the ring and the base is concentrated at the further edge of the ring, as illustrated in Figs. 4(b), (d) and (f).

Furthermore, it was observed that the cover rotated anti-clockwise, Fig. 4, while lowering its center in such a way that the coverstem slid upward over the inner wall of the ring. This might seem to be, but is not, in contradiction with the behaviour of the ring, which tends to pivot very little around location $(1)$, because of the frictional forces exerted by the powder on the inner wall of the ring. The resultant $F$ of these frictional forces is indicated in Fig. 4(f). The resultant $R$ of the horizontal forces exerted by the bulk material on the inner wall of the ring is supposed to apply at a fraction $\theta$ of the ring height $h$ from the bottom, Fig. 4(f). For identical assumptions as stated in the previous paragraph for the original version of the Jenike tester, it follows

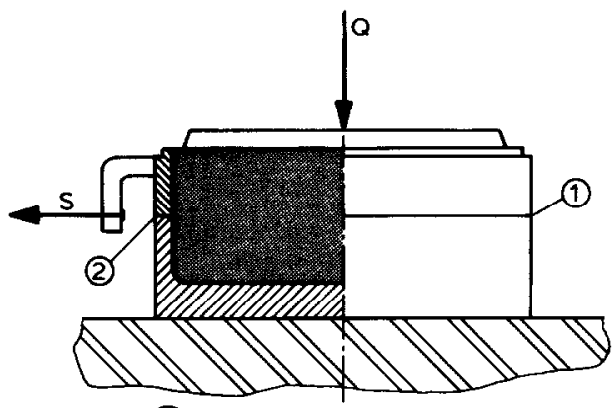

(a)
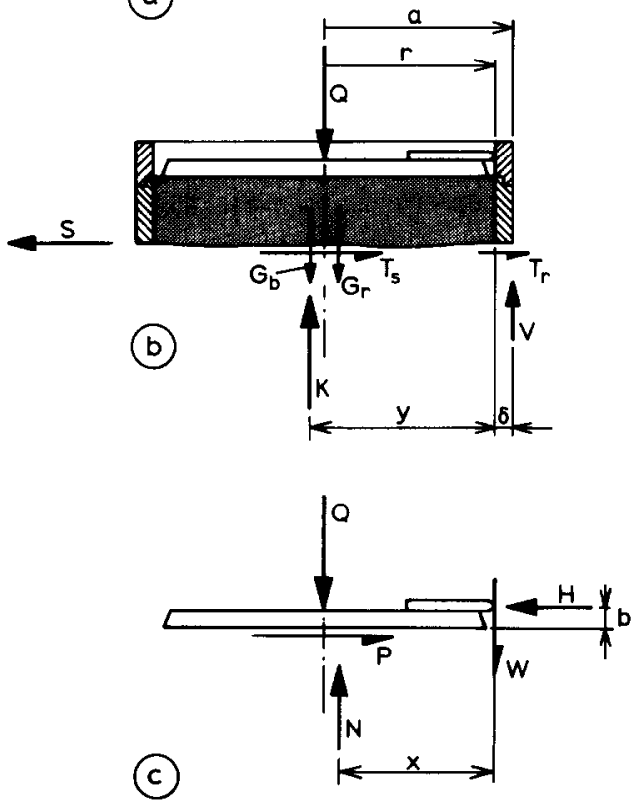
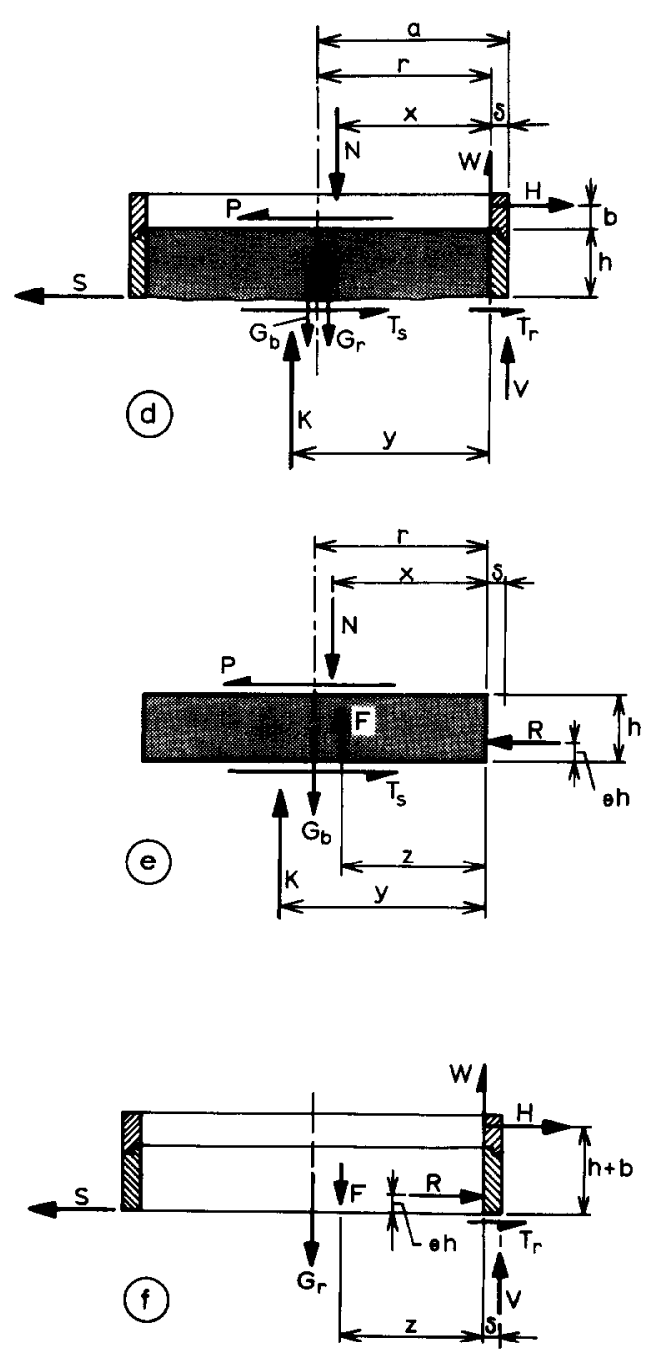

Fig. 4. Illustration of the real normal force $K$ and shear force $T_{s}$ exerted on the plane of shear of the bulk solid in case of the modified Jenike shear cell. 
for the corrected normal and shear stress that

$$
\begin{aligned}
\sigma_{\mathrm{c}} & =\frac{K}{A}=(1-\Omega)\left(1+\mu_{\mathrm{d}} \epsilon \frac{\tau}{\sigma}\right) \sigma+\sigma_{\mathrm{b}} \\
\tau_{\mathrm{c}} & =\frac{T_{\mathrm{s}}}{A} \\
& =\left\{\left[1+(1-\Omega) \mu_{\mathrm{r}} \mu_{\mathrm{d}} \epsilon\right]-\mu_{\mathrm{r}}\left(\Omega+\frac{\sigma_{\mathrm{r}}}{\sigma}\right) \frac{\sigma}{\tau}\right\} \tau
\end{aligned}
$$

in which $\sigma_{\mathrm{b}}$ and $\sigma_{\mathrm{r}}$ are determined by eqn. (4). To what extent the unconfined yield pressures, the flow functions, and the effective coefficients of friction are affected by the corrected values of $\sigma$ and $\tau$, can be found in the same way as followed in the section on Correction factors for the Jenike tester. The corresponding correction factors are also summarised in Tables 1 and 2.

\section{Discussion of the theoretical results}

1 The conclusions drawn in this section hold for the following:

(i) The assumptions stated in the preceding paragraphs will hold for both the consolidation and shear phases.

(ii) In order to avoid data congestion, the variation of the parameters has been limited. The coefficients of friction $\mu_{\mathrm{p}}$ and $\mu_{\mathrm{d}}$ and also the fraction of the shear force transmitted by the cover $\epsilon$ were not varied in these experiments.

Although our complete work [5] contains graphs of the correction factors as a function of variations of $\psi, \mathbf{n}$ and $\mu_{\mathrm{e}}$, for the sake of brevity Tables 1 and 2 contain only the maximum and minimum values of these factors (upper data).

The lower data refer to the case of fixed values for $\psi, n$ and $\mu_{\mathrm{e}}$ according to the lower right corner of the figures. It is emphasized that in Table 1 the body forces of the ring and its contents are neglected. Although the spread is still considerable, the best results seem to be obtained with the modified cell when both ring and base rim are cleaned before each test $\left(\mu_{\mathrm{r}}=0.2\right)$. One may not conclude however, for whatever reason, that this must necessarily be the case, since the correction factors are the result of several disturbing factors, each producing its own positive or negative contribution. Moreover, this effect is determined in the first place by the first derivatives of a yield locus in its respective points relative to $\mu_{r}$. In reality, all cases between clean and dirty may occur $(0.2 \lessgtr$ $\mu_{\mathrm{r}} \leqslant \mu_{\mathrm{e}}$ ). This is only one reason for which it takes considerable experience to operate this type of cell correctly. From the computer programme it followed that ringlifting $(V<0)$ occurred only rarely and is therefore not indicated in the figures.

\section{EXPERIMENTS}

\section{Introduction}

As can be seen from the foregoing analysis, several parameters are involved in the correction of the results from both the Jenike tester and the modified Jenike tester.

A series of experiments has been carried out to establish the magnitude of these parameters and to verify experimentally some of the assumptions on which the analysis is based.

Moreover, an attempt is made to eliminate the influence of the parameters concerned in the experiments in order to obtain the correct results directly.

\section{Experiments with the Jenike shear tester}

The experiments are carried out with a tester similar to a Jenike shear tester, apart from some modifications to perform special measurements. All tests were done with three materials, bentonite, dolomite and titanium dioxide.

\section{Friction between ring and base}

With the tester empty, the ring was loaded by the loading mechanism and pulled over the base by the shearing device. For both the dirty and clean ring-base contact the shearing force was measured as a function of the load $Q$. Despite some scatter, in all situations a reasonable mean value for the coefficient of friction $\mu_{\mathrm{r}}$ could be established within the variations of $Q$ considered. For all materials, the coefficient of friction for the dirty case was $\left(\mu_{x} \approx 0.40-0.49\right)$ considerably higher than for the clean ring-base contact $\left(\mu_{\mathrm{x}} \simeq\right.$ $0.19)$.

The fraction of the shearing force trasmitted by the cover

To estimate this fraction $\epsilon$, we measured the contact force between pin and ring by a small 
piezo-electric force transducer, used as a pin. These measurements were performed with covers of various diameters (up to $\mathbf{1 5}$ mm radial clearance between cover and ring) and roughness. From the results it can be concluded that the cover transmits a substantial fraction of the shearing force ( $50-60 \%)$ and that the magnitude of $\epsilon$ is independent of the radial clearance and the roughness of the cover.

\section{Friction between pin and ring}

To measure the friction between the ring and the piezo-electric force transducer used as a pin, we placed the ring in a vertical position on the vertically clamped pin. The ring was then loaded with a vertical force $V$ and pushed over the pin by the shearing device of the shear tester. Within the variations of $V$ considered $(20-90 \mathrm{~N})$, the value of the coefficient of friction could be taken as approximately constant, $\mu_{\mathrm{p}} \approx 0.20$.

The fraction of the vertical force on the material transmitted to the ring

To obtain the value of this fraction $\Omega$ experimentally, we fixed vertically three thin steel wires at equal distances at the circumference of the ring, by which the ring could be lifted. The wires were attached to a force transducer, which measured the force $R_{v}$ necessary to lift the ring. The ring was lifted at the end of the consolidating stage and at the start of yielding in the shearing stage. From the measurements of $R_{v}$ the value of $\Omega$ can be estimated by subtracting the friction between pin and ring, which equals $(1-\epsilon) S \mu_{\mathrm{p}}$. From our measurements with several materials and vertical loads, we estimated $\Omega$ in the range from $0.23-0.45$. These values are probably too high, due to the difficulty in raising the ring purely vertically, but indicate that $\Omega$ cannot be neglected.

The contact between ring and base during shear tests

To verify the contact between ring and base during a shear test, we connected both parts to an electric resistance meter. As long as contact exists, even with a very thin layer of material between ring and base, the resistance was very low. When the ring was lifted from the base, over a distance of $>0.02 \mathrm{~mm}$, there was a sharp increase in the resistance.
During the tests, we established contact in all cases between ring and base at the end of the consolidation and during the relevant part of the shearing stage. When, after incipient failure, the shearing proceeded, the contact diminished, due to the expansion of the material.

\section{Sliding of the pin over the ring}

To establish the vertical displacement of two points of the cover, two dial gauges were positioned vertically between the cover and a rigidly supported beam. From these results the vertical displacement of the bracket, in particular the free end of the pin, could be calculated. We also measured the movement of the pin directly by a fiber optic scanner positioned vertically above the free end of the pin. The scanner being attached to the ring, the change in the light reflection was a direct measure of the relative vertical movement of the pin. Both types of measurement confirmed that at the end of the steady state the pin tends to stand still against the ring. Only in a few cases the pin kept sliding downward or even start moving upward over the ring. At incipient failure, in all cases either no relative movement or upward sliding of the pin was established.

\section{The real normal force $K$ on the assumed} shear plane

To measure this force directly, we modified the base of the shear tester, according to Fig. 5. The base was supported by a load cell,

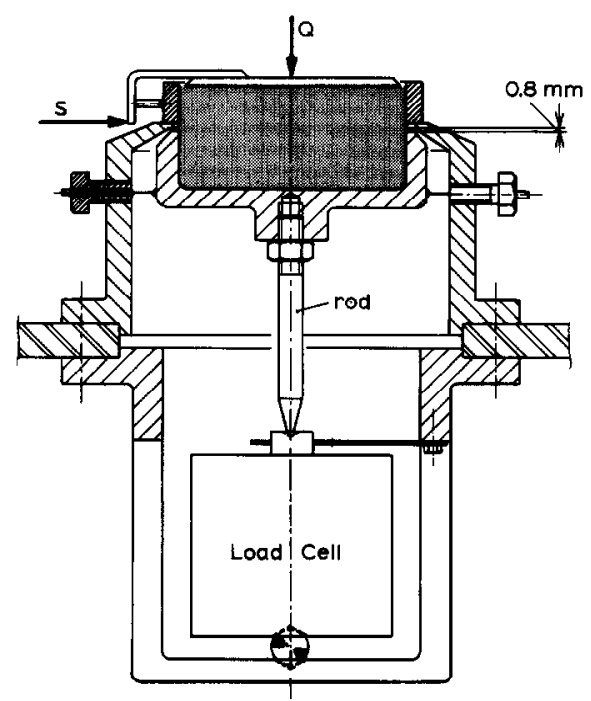

Fig. 5. Modification of the shear cell to measure the real normal force on the plane of shear. 
which measured the vertical force, horizontal movement of the base being constrained by four adjustable steel wires. To avoid contact between ring and base, a thin ring was positioned above, but free from, the base, over which the ring could slide. From the meaurements it was established that at the end of the consolidating stage the value of $K$ is nearly constant. At or just before the start of incipient failure, in all cases an increase in $K$ was noticed.

\section{Experiments with the modified shear tester}

To eliminate the influence of the bracket and the pin, we slightly modified the shear tester. The bracket on the cover was omitted and the shearing force directly transmitted to a special bracket on the ring. In some preliminary tests it turned out that pulling the ring instead of pushing it was easier to perform and led to a more stable ring movement. So in further experiments we pulled the ring via a flexible steel wire between the bracket and the load cell, the shearing force being introduced level with the shear plane. It was observed during some tests that the cover tended to climb the ring at the back, due to a rotation of the cover. To prevent this and to avoid a sharp contact between cover and ring, the cover was provided with a Teflon-coated stem and the height of the ring extended by a low extra ring. As in the case of the Jenike tester, we investigated the contact between ring and base with an electric resistance meter, which revealed that in the relevant stages of the test, contact was always maintained. In many cases, however, at the front a small gap arose between ring and base, so it can be concluded that the contact force will exist mainly at the rear of the ring.

We also measured the rotation of the cover with dial gauges and the fiber optic scanner as described above. These tests indicated that in all cases the stem on the back of the cover slid only upward over the inside of the ring. Also, the real normal force $K$ on the shear plane was measured directly with the device as shown in Fig. 6 . The behaviour of $K$ was about the same as noticed with the Jenike shear tester.

With the modified version also, a fraction $\Omega$ of the normal load on the material will be transmitted to the ring. This fraction could be measured with the same lifting device as used with the Jenike tester.

In this case, however, the contact force between cover and ring, due to the shearing action, is not known, leading to an unknown vertical friction $W$ between cover and ring when the ring is lifted. This frictional force $W$ could only be approximated by an assumption about the distribution of the shearing force over the cover and the ring. Assuming $\epsilon$ $=0.5$, the corresponding values for $\Omega$ ranged from $0.20-0.50$ for the materials used. The high level of $\Omega$ and scatter in the results is mainly caused by the lifting of the ring not being purely vertical. The results, however, indicate that $\Omega$ plays an important role in the tests.

\section{Discussion of the experimental results}

With both the Jenike and the modified shear tester, yield loci were measured for bentonite, dolomite and titanium dioxide. These measurements included a normal test procedure and a correction of the results with the aid of the measured parameters. Furthermore, some tests were performed where the ring was lifted by hand from the base, half-way through the consolidating stage, to avoid the influence of $\Omega$ and the ring-base contact. Complete results of all measurements have been published [5] .

\section{Results with the Jenike shear tester}

Complete results and corrections for bentonite are given in Table 3 and the corresponding yield loci in Fig. 6, together with the derived values for $\sigma_{\mathrm{p}}$ and $\sigma_{\mathrm{l}}$. The values for $\Omega$ are calculated from the measured $K$-values and the pin friction $\mu_{\mathrm{p}}$. However, because $\Omega$ depends on the magnitude and the direc-

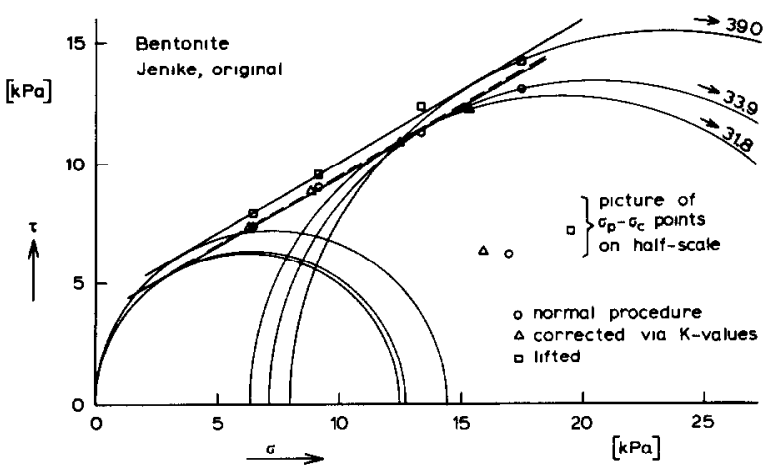

Fig. 6. Results with original Jenike shear cell on bentonite. 
TABLE 3. Jenike tester: results and corrections on bentonite, $\mu_{r}=0.40$

\begin{tabular}{|c|c|c|c|c|c|c|c|c|c|c|c|}
\hline \multicolumn{6}{|c|}{ Steady state } & \multicolumn{6}{|c|}{ Incipient failure } \\
\hline$\frac{Q_{\mathrm{w}}}{A}$ & $\begin{array}{l}\frac{S}{A} \\
(\mathrm{kPa})\end{array}$ & $\begin{array}{l}\frac{K}{A} \\
(\mathrm{kPa})\end{array}$ & $\begin{array}{l}\Omega_{\min } \\
(-)\end{array}$ & $\begin{array}{l}\Omega_{\max } \\
(-)\end{array}$ & $\begin{array}{l}\frac{S_{\mathrm{c}}}{A} \\
(\mathrm{kPa})\end{array}$ & $\begin{array}{l}\frac{Q_{\mathrm{w}}}{A} \\
(\mathrm{kPa})\end{array}$ & $\begin{array}{l}\frac{S}{A} \\
(\mathrm{kPa})\end{array}$ & $\begin{array}{l}\frac{K}{A} \\
(\mathrm{kPa})\end{array}$ & $\begin{array}{l}\Omega_{\min } \\
(-)\end{array}$ & $\begin{array}{l}\Omega_{\max } \\
(-)\end{array}$ & $\begin{array}{l}\frac{S_{\mathrm{c}}}{A} \\
(\mathrm{kPa})\end{array}$ \\
\hline 17.49 & 13.29 & 15.65 & 0.01 & 0.15 & 12.55 & 13.34 & 11.21 & 12.47 & $<0$ & 0.11 & 10.86 \\
\hline 17.49 & 13.15 & 15.60 & 0.01 & 0.15 & 12.39 & 13.34 & 11.18 & 12.55 & $<0$ & 0.10 & 10.87 \\
\hline 17.49 & 13.01 & 14.77 & 0.06 & 0.20 & 11.92 & 13.34 & 11.10 & 12.61 & $<0$ & 0.10 & 10.81 \\
\hline 17.49 & 13.31 & 15.46 & 0.02 & 0.16 & 12.50 & 13.34 & 11.49 & 12.17 & $<0$ & 0.14 & 11.02 \\
\hline 17.49 & 13.01 & 15.46 & 0.02 & 0.16 & 12.20 & 13.34 & 11.29 & 12.61 & $<0$ & 0.10 & 11.00 \\
\hline 17.49 & 12.73 & 15.32 & 0.03 & 0.17 & 11.87 & 9.19 & 8.80 & 8.86 & $<0$ & 0.10 & 8.60 \\
\hline 17.49 & 13.12 & 15.68 & 0.01 & 0.15 & 12.40 & 9.19 & 8.97 & 8.40 & $<0$ & 0.13 & 8.65 \\
\hline 17.49 & 13.07 & 15.16 & 0.04 & 0.17 & 12.13 & 9.19 & 9.13 & 9.01 & $<0$ & 0.07 & 9.07 \\
\hline 17.49 & 13.15 & 15.04 & 0.04 & 0.18 & 12.17 & 9.19 & 9.25 & 8.82 & $<0$ & 0.09 & 9.09 \\
\hline 17.49 & 13.01 & 15.47 & 0.00 & 0.14 & 12.31 & 9.19 & 8.97 & 9.19 & $<0$ & 0.05 & 8.97 \\
\hline 17.49 & 12.84 & 15.35 & 0.03 & 0.16 & 11.99 & 6.42 & 7.22 & 6.10 & $<0$ & 0.09 & 7.10 \\
\hline 17.49 & 12.73 & 14.85 & 0.06 & 0.19 & 11.68 & 6.42 & 7.34 & 6.19 & $<0$ & 0.08 & 7.24 \\
\hline 17.49 & 13.29 & 15.32 & 0.03 & 0.17 & 12.41 & 6.42 & 7.47 & 6.42 & $<0$ & 0.05 & 7.47 \\
\hline 17.49 & 13.15 & 15.52 & 0.02 & 0.16 & 12.36 & 6.42 & 7.25 & 6.42 & $<0$ & 0.05 & 7.25 \\
\hline 17.49 & 13.23 & 15.43 & 0.02 & 0.16 & 12.41 & 6.42 & 7.56 & 6.42 & $<0$ & 0.05 & 7.56 \\
\hline
\end{tabular}

tion of the pin frictional force $W$, only the boundary values can be calculated. The actual values will lie between these boundaries. The formulas used are

$$
\begin{aligned}
& \begin{array}{l}
N=Q_{1} \pm W_{\max } \quad \begin{array}{l}
+ \text { upward moving pin } \\
- \text { downward moving pin }
\end{array} \\
\begin{aligned}
W_{\max } & =\mu_{\mathrm{p}} H \\
& =\mu_{\mathrm{p}}(1-\epsilon) S \approx 0.5 \mu_{\mathrm{p}} S
\end{aligned} \\
F=N-K \\
\Omega=\frac{F}{N}
\end{array}
\end{aligned}
$$

The very low or even negative values calculated for $\Omega_{\mathrm{min}}$, see Table 3 , clearly indicate that in these cases the pin did not slide downward over the ring. These calculations confirm the observations of the pin movement as described in the section on Experiments with the Jenike shear tester.

From the measurements the real normal and shear forces on the shear plane could also be established. The real normal force $\left(K=Q_{c}\right)$ was measured directly and the real shear force calculated by

$S_{\mathrm{c}}=S-\left(Q_{\mathrm{w}}-K\right) \mu_{\mathrm{r}}$

It is seen from Table 3 and Fig. 6 that the differences between the direct results from the normal test procedures and those derived from the real forces on the shear plane are most pronounced for the steady state. For the incipient failure points, especially at low stress levels, the deviations are very small as the $K$-values tend to equal $Q_{w}$. The differences in the yield loci, however, imply that the $\sigma_{1} / \sigma_{p}$ ratio as well as the value of $\mu_{e}$ are also changed.

Compared with the yield locus from the normal tests, it is seen in Fig. 6 that the tests where the ring was lifted by hand led to higher results. This is plausible, since there is no influence from the ring-base contact when the ring is lifted. However, in the corrected yield locus, this influence is eliminated by calculation, so at first sight one should expect comparable results for the lifted ring and the corrected results. But in the case of the lifted ring, the total load $Q_{w}$ acts upon the sample, leading to a more consolidated material and a somewhat higher yield locus, as confirmed by the tests. If we look at the values of $\sigma_{1} / \sigma_{p}$ and $\phi_{\mathrm{e}}$ (which can be derived from the $\sigma_{1}$-circles), we may expect to find about the same values for the corrected and lifted results. This holds rather well for bentonite, but for the other materials the lifted ring tests led to higher results. This is most probably caused by the difficulty in raising the ring purely vertically, the same problem as dealt with in the determination of $\Omega$-values. 


\section{TABLE 4}

Modified tester: results and corrected results on bentonite, $\mu_{r}=0.40$

\begin{tabular}{|c|c|c|c|c|c|c|c|c|c|}
\hline \multicolumn{5}{|c|}{ Steady state } & \multicolumn{5}{|c|}{ Incipient failure } \\
\hline $\begin{array}{l}\frac{Q_{\mathrm{w}}}{A} \\
(\mathrm{kPa})\end{array}$ & $\begin{array}{l}\frac{S}{A} \\
(\mathrm{kPa})\end{array}$ & $\begin{array}{l}\frac{K}{A} \\
(\mathrm{kPa})\end{array}$ & $\begin{array}{l}\Omega \\
(-)\end{array}$ & $\begin{array}{l}\frac{S_{\mathrm{c}}}{A} \\
(\mathrm{kPa})\end{array}$ & $\begin{array}{l}\frac{Q_{\mathrm{w}}}{A} \\
(\mathrm{kPa})\end{array}$ & $\begin{array}{l}\frac{S}{A} \\
(\mathrm{kPa})\end{array}$ & $\begin{array}{l}\frac{K}{A} \\
(\mathrm{kPa})\end{array}$ & $\begin{array}{l}\Omega \\
(-)\end{array}$ & $\begin{array}{l}\frac{S_{\mathrm{c}}}{A} \\
(\mathrm{kPa})\end{array}$ \\
\hline $\begin{array}{l}17.48 \\
17.84 \\
17.84 \\
17.84 \\
17.84 \\
17.84\end{array}$ & $\begin{array}{l}12.96 \\
13.84 \\
13.56 \\
13.84 \\
13.76 \\
13.76\end{array}$ & $\begin{array}{l}15.04 \\
15.46 \\
15.63 \\
15.40 \\
16.43 \\
15.82\end{array}$ & $\begin{array}{l}0.18 \\
0.16 \\
0.15 \\
0.17 \\
0.11 \\
0.14\end{array}$ & $\begin{array}{l}11.83 \\
12.89 \\
12.68 \\
12.87 \\
13.20 \\
12.95\end{array}$ & $\begin{array}{r}13.68 \\
13.68 \\
9.53 \\
9.53 \\
6.76 \\
6.76\end{array}$ & $\begin{array}{r}11.07 \\
11.85 \\
9.38 \\
9.36 \\
7.92 \\
7.64\end{array}$ & $\begin{array}{r}11.67 \\
11.72 \\
8.40 \\
8.12 \\
6.55 \\
6.35\end{array}$ & $\begin{array}{l}0.17 \\
0.17 \\
0.13 \\
0.16 \\
0.04 \\
0.06\end{array}$ & $\begin{array}{r}10.27 \\
11.06 \\
8.93 \\
8.79 \\
7.83 \\
7.48\end{array}$ \\
\hline
\end{tabular}

\section{Results with the modified tester}

The results for bentonite with the modified device are given in Table 4 and Fig. 7. In this case the direction of the frictional force $W$ against the ring is always the same, so only one value of $\Omega$ needs to be calculated. The formulas used are the same as with the Jenike tester, with $\mu_{\mathrm{d}}$ and $\epsilon$ instead of $\mu_{\mathrm{p}}$ and $(1-\epsilon)$ respectively.

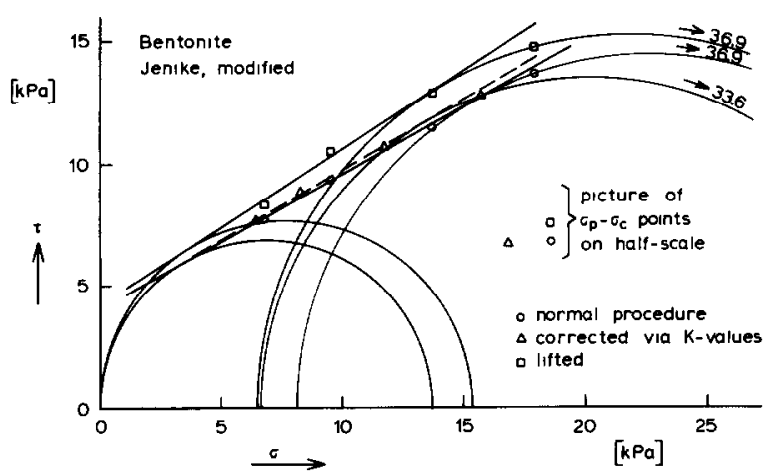

Fig. 7. Results with modified shear cell on bentonite.
Comparison of the results from the normal tests, the corrected results, and the results with the ring lifted from the base, gives the same picture as in the case of the Jenike tester.

\section{COMPARISON OF THE THEORETICAL AND EXPERIMENTAL RESULTS}

Comparison of the theoretical and experimental results is greatly simplified by making use of the correction factors. The theoretical correction factors can be calculated by approximating the measured yield loci by the best-fitting Warren-Spring curves and using the correction formulas of the section on Analysis. The experimental correction factors can be derived from the measured and corrected yield loci.

The boundary values of both correction factors, as determined for the Jenike and the modified shear tester, are given in Table 5.

\section{TABLE 5}

Comparison of theoretical and experimental correction factors.

\begin{tabular}{|c|c|c|c|c|}
\hline & \multicolumn{4}{|c|}{$\begin{array}{l}\text { Boundary values of the correction factors in connection with the experiments } \\
\Omega_{\text {th }}=0-0.2 \mu_{\mathrm{p}}=0.2 \mu_{\mathrm{d}}=0.2 \mu_{\mathrm{r}}=0.40-0.49 \epsilon=0.5\end{array}$} \\
\hline & \multicolumn{2}{|c|}{ Jenike, original } & \multicolumn{2}{|c|}{ Jenike, modified } \\
\hline & Theoretical & Experimental & Theoretical & Experimental \\
\hline $\begin{array}{l}\mathrm{CF}_{\text {op }} \\
\mathrm{CF}_{\text {ff }} \\
\mathrm{CF}_{\mu \mathrm{e}} \\
\mathrm{CF}_{\mathrm{yl}}\end{array}$ & $\begin{array}{l}1.01-1.18 \\
0.68-1.00 \\
1.02-1.36 \\
1.00-1.11\end{array}$ & $\begin{array}{l}1.00-1.02 \\
0.91-1.00 \\
1.00-1.13 \\
1.00-1.02\end{array}$ & $\begin{array}{l}1.03-1.14 \\
0.76-0.95 \\
0.99-1.17 \\
0.99-1.08\end{array}$ & $\begin{array}{l}1.00-1.04 \\
0.91-0.92 \\
1.03-1.08 \\
1.00-1.03\end{array}$ \\
\hline
\end{tabular}


This figure confirms that the experimental results are between the boundaries of the theoretical correction factors.

It is also seen that the experimental correction factors for the yield loci and the unconfined yield strength $\sigma_{\mathrm{p}}$ are close to unity, and the correction factor found for the flow function and the internal friction are still considerable. We have only compared the results for the dirty ring here, since we did no cleaning between the measurements. It is obvious that measurements with a clean ring, assuming the same $\Omega$-values, would have required somewhat greater corrections in our case.

\section{CONCLUSIONS}

\section{Conclusions arising from the theory}

(1) The locations of the resultant forces on the top and bottom of the bulk solid in the ring do not shift excessively from the centre. Moreover, their location is almost independent of the fraction of the shear force $(\epsilon)$ transmitted by the cover [5].

(2) The tilt of the cover is predictable within $10 \%$ accuracy [5].

\section{Conclusions arising from the experiments}

(1) A considerable part $\epsilon$ of the shearing force is transmitted to the material by the cover, typically ranging from 0.48 to $\mathbf{0 . 6 0}$. This fraction appeared to be nearly independent of the roughness of the cover and the gap between cover and ring.

(2) In the majority of tests with the Jenike shear cell, the pin did not move over the ring at the end of the consolidation phase. Only rarely did the pin move either up or down. At incipient failure in all cases the pin did not slide at all or was sliding upward.

In the case of the modified tester the stem on the cover slid only upward over the inner surface of the ring.

(3) The correction factors for the yield locus and the unconfined yield strength $\left(\mathrm{CF}_{\mathrm{YL}}\right.$ and $\mathrm{CF}_{\mu}$, respectively) were rather low $(\leqslant 1.04)$ and tend to disappear in the normal scatter of the measurements. The deviations for $\mu_{\mathrm{e}}$ and the flow function (up to 13 and $10 \%$ respectively), cannot, however, be neglected.
(4) The artificial ring lifting, as performed in our tests, did not lead to reliable results. An improved procedure, however, might provide the correct results directly.

\section{Conclusions arising from both theory and experiments}

The vertical force $K$ on the shear plane was in nearly all cases smaller than the applied total load $Q_{w}$. For the Jenike shear tester, steady state values for $K$ were $3-16 \%$ lower than $Q_{w}$. For incipient failure, lower values from 0 to $9 \%$ were established, the smaller deviations always occurring at the lowest $\sigma$ level, where $K$ tends to equal $Q_{w}$. Deviations found for the modified tester were 5 - 16\% for the steady state and $3-15 \%$ for incipient failure, respectively.

(2) At all relevant stages in the shear tests, a contact was maintained between ring and base. In a few cases, especially at the lower $\sigma$-values, diminishing contact tended to occur on the run to incipient failure, and most often when shearing proceeded after passing the maximum value.

(3) The friction between ring and base, $\mu_{x}$, is higher in the case of a dirty ring, and also closer to the 'internal' friction of the material than in the case of a cleaned ring. However, it cannot be concluded that in general a dirty ring-base contact will lead to better results, because this depends strongly on the material that has to be measured.

(4) The fraction of the real force exerted on the top of the sample which is transmitted via friction at the ring inner wall $(\Omega)$ will rarely exceed $20 \%$.

\section{General conclusions}

The averaged deviation from unity of most of the experimentally determined correction factors amounts to approximately $25 \%$ and $40 \%$ of the theoretical boundaries for the original and modified Jenike shear cell. It is hard to say which of the two methods, either pushing or towing the ring, will lead to the best results. However, since the ring is supposed to perform pure translation in one plane only, one may tend to conclude that towing is the better of the two.

(2) The behaviour of the ring in the case of the modified tester was more stable than for the original device. 
(3) Relatively high deviations of the unconfined yield pressure need not correspond to high deviations of the flow function and vice versa.

(4) It may be concluded that the yield loci and their characteristic derivatives, as determined by the Jenike shear cell, are, as a rule, well suited for design purposes as regards the magnitudes of the correction factors. The authors have discussed elsewhere [6] their view that for comparative measurements of the properties of bulk materials for research purposes the triaxial tester is to be preferred to the shear tester.

\section{LIST OF SYMBOLS}

A cross-sectional area of sample, $\mathrm{m}^{2}$

$C$ cohesion, $\mathrm{N} \cdot \mathrm{m}^{-2}$

$\mathrm{CF}_{\mathrm{ff}}$ correction factor for the flow function,

$\mathrm{CF}_{\mathrm{yl}}$ correction factor for the yield locus, -

$\mathbf{C F}_{\text {op }}$ correction factor for the unconfined yield stress, -

$\mathrm{CF}_{\mu_{\mathrm{e}}}$ correction factor for the effective coefficient of friction, -

$F$ vertical component of the wall frictional force, $N$

ff flow function, $\sigma_{\mathrm{g}} / \sigma_{\mathrm{p}},-$

$G_{\mathrm{b}} \quad$ weight of bulk solid sitting inside the ring, $\mathrm{N}$

$G_{\mathrm{r}} \quad$ weight of the ring, $\mathrm{N}$

$K$ vertical component of force on sample shear plane, $\mathrm{N}$

$N$ external applied force plus or minus the frictional vertical force exerted by the pin, $\mathbf{N}$

$n$ curve parameter in the Warren-Spring equation,

$Q$ summation of the external vertical load and the weight of the cover, $\mathrm{N}$

$Q_{1}$ summation of the external vertical load, weight of the cover and material inside the ring, $N$

$Q_{w}$ total load above the base, $N$

$\boldsymbol{R}$ horizontal component of the wall friction, force, $\mathrm{N}$

$S$ external horizontal applied (shear) force on bracket, $\mathrm{N}$

$T$ tensile strength of sample, material, $\mathbf{N} \cdot \mathrm{m}^{-2}$
$T_{s} \quad$ horizontal component of force on sample shear plane, $\mathrm{N}$

$V$ vertical component of force on ring bottom, $\mathbf{N}$

$W$ vertical component of the pin force in case of the original cell, or of the cover stem force of the modified cell, $\mathrm{N}$

$\epsilon \quad$ part of the (shear) force $S$ transmitted to the sample by the cover, -

$\mu_{d} \quad$ coefficient of friction referring to contact between ring and cover stem, in case of modified shear cell, -

$\mu_{\mathrm{e}} \quad$ effective coefficient of friction of the bulk material, -

$\mu_{p}$ coefficient of friction referring to contact between bracket pin and ring exterior,

$\mu_{x} \quad$ coefficient of friction referring to contact between ring and base, -

$\sigma$ compressive stress, $\mathrm{N} \cdot \mathrm{m}^{-2}$

$\sigma_{\mathrm{b}}$ normal stress on shear plane due to the weight of bulk solid inside the ring, $N$ $\mathrm{m}^{-2}$

$\sigma_{c} \quad$ corrected value of $\sigma, \mathrm{N} \cdot \mathrm{m}^{-2}$

$\sigma_{\mathrm{p}}$ unconfined yield pressure, $\mathrm{N} \cdot \mathrm{m}^{-2}$

$\sigma_{\mathrm{r}}$ normal stress on shear plane due to the weight of the ring, $\mathrm{N} \cdot \mathrm{m}^{-2}$

o major consolidation stress, $\mathrm{N} \cdot \mathrm{m}^{-2}$

$\tau$ shear stress, $\mathrm{N} \cdot \mathrm{M}^{-2}$

$\tau_{\mathrm{a}}$ auxiliary shear stress, $\mathrm{N} \cdot \mathrm{m}^{-2}$

$\tau_{\mathrm{c}} \quad$ corrected value of $\tau, \mathrm{N} \cdot \mathrm{m}^{-2}$

$\phi_{\mathrm{e}} \quad$ effective angle of friction, $\mathrm{rad}$

$\psi \quad$ cohesion related to tensile strength $(\psi=$ $C / T),-$

$\Omega \quad$ part of $N$ transmitted to the wall of the ring $(F=\Omega N)$, -

\section{REFERENCES}

1 A. W. Jenike, Gravity Flow of Bulk Solids, Utah Engng. Exper. Station, Univ. of Utah, Bul, 108, 1961.

2 A. W. Jenike, Storage and Flow of Solids, Utah Engng. Exper. Station, Univ. of Utah, Bul. 123, 1964, revised 1970.

3 J. Schwedes, Fliessverhalten von Schüttgütern in Bunkern, Verlag Chemie, Weinheim, F.R.G., 1968.

4 M. D. Ashton, D. C. Cheng, R. Farley and F. H. Valentin, Rheol. Acta, 4 (1965) 206.

5 F. J. C. Rademacher and G. Haaker, VDIForschungsheft, 629 (June 1985), VDI-Verlag, Diisseldorf, F.R.G.

6 G. Haaker and F. J. C. Rademacher, Aufbereitungstechnik, 11 (1983) 647 . 